\title{
Regulation of hematopoiesis and the hematopoietic stem cell niche by Wnt signaling pathways
}

\author{
Michael J Nemeth ${ }^{1}$, David M Bodine ${ }^{1}$ \\ ${ }^{1}$ Hematopoiesis Section, Genetics and Molecular Biology Branch, National Human Genome Research Institute, Building 49, Room \\ 3A18, 49 Convent Dr., MSC 4442, Bethesda, MD 20892-4442, USA
}

Hematopoietic stem cells (HSCs) are a rare population of cells that are responsible for life-long generation of blood cells of all lineages. In order to maintain their numbers, HSCs must establish a balance between the opposing cell fates of self-renewal (in which the ability to function as HSCs is retained) and initiation of hematopoietic differentiation. Multiple signaling pathways have been implicated in the regulation of HSC cell fate. One such set of pathways are those activated by the Wnt family of ligands. Wnt signaling pathways play a crucial role during embryogenesis and deregulation of these pathways has been implicated in the formation of solid tumors. Wnt signaling also plays a role in the regulation of stem cells from multiple tissues, such as embryonic, epidermal, and intestinal stem cells. However, the function of Wnt signaling in HSC biology is still controversial. In this review, we will discuss the basic characteristics of the adult HSC and its regulatory microenvironment, the "niche", focusing on the regulation of the HSC and its niche by the Wnt signaling pathways.

Keywords: hematopoiesis, hematopoietic stem cell, Wnt proteins, osteoblast

Cell Research (2007) 17:746-758. doi: 10.1038/cr.2007.69; published online 4 September 2007

\section{The hematopoietic stem cell}

The function of the hematopoietic stem cell (HSC) is to initiate hematopoiesis, the process by which all mature blood cells, which have a limited life span, are continuously produced throughout the life of the organism. HSCs are the only bone marrow cells capable of differentiating into all blood cell lineages [1-3]. In the adult mouse, the frequency of HSCs is approximately 1 in 10000 bone marrow cells $(0.01 \%)$ [4-7]. Hematopoiesis is generally depicted as a hierarchical process (Figure 1) in which the HSC sits at the top of the hierarchy. HSCs differentiate into hematopoietic progenitor cells that are capable of exponential proliferation as well as continuing the process of differentiation. After terminal differentiation, the functional

Correspondence: Michael J Nemeth

Tel: +1-301-451-9172; Fax: +1-301-402-4929

E-mail: mnemeth@nhgri.nih.gov cells of the hematopoietic system are generated. Terminally differentiated blood cells can be classified into myeloid and lymphoid cells. Myeloid cells include red blood cells, platelets, and cells responsible for cellular immunity such as macrophages and granulocytes. Lymphoid cells, which are involved in humoral immunity, are T, B, and natural killer cells. There are between 6 and $9 \times 10^{8}$ total cells (nucleated white blood cells and red blood cells) in the mouse bone marrow, a ratio greater than $10^{4}$ bone marrow cells per single HSC [8].

The life span of differentiated hematopoietic cells can range from years in the case of $\mathrm{T}$ and $\mathrm{B}$ cells involved in immunological memory, to 3 months in the case of red blood cells, to days, in the case of granulocytes. Therefore, HSCs are constantly called upon to supply a steady stream of hematopoietic progenitors that can generate new hematopoietic cells. Given the massive rate of hematopoietic cell turnover (e.g., daily turnover in the human body is estimated to be $1 \times 10^{12}$ cells [9]), there are not nearly enough HSCs to continuously replenish mature blood cells 


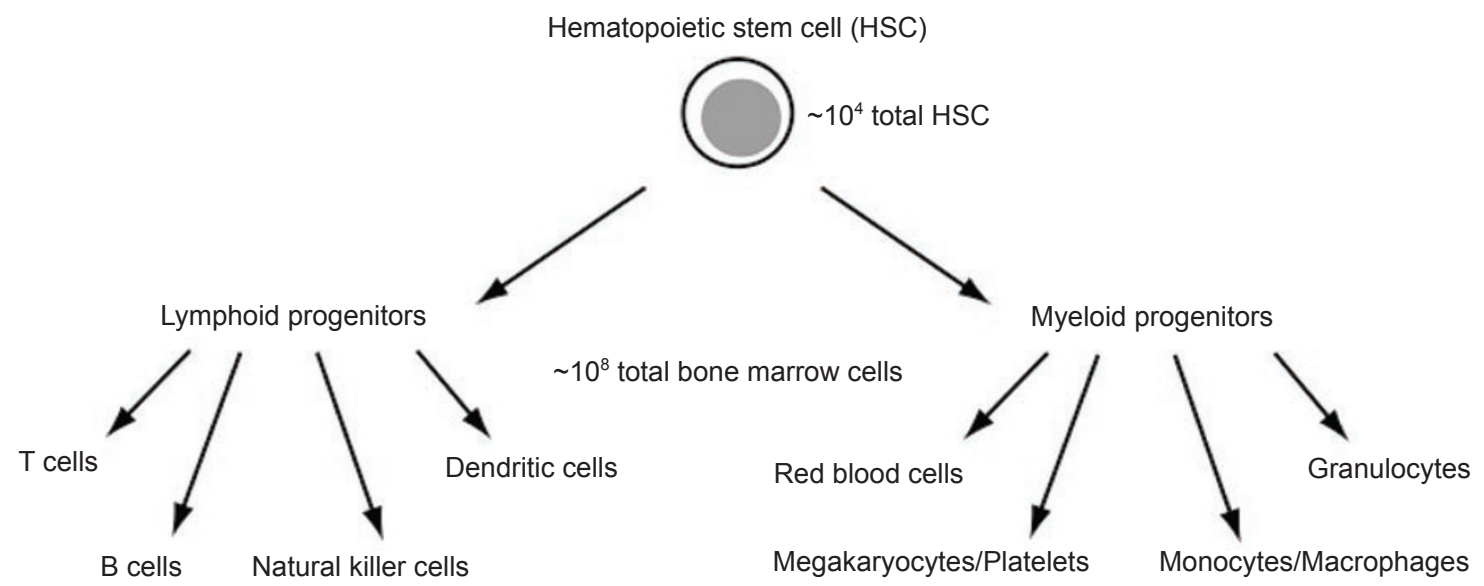

Figure 1 A simplified schematic diagram of the hematopoietic hierarchy. The hematopoietic stem cell (HSC) sits at the top of the hierarchy. Upon activation, the HSC is capable of differentiating into clonal progenitors that can expand exponentially as well as continue the process of differentiating. Hematopoietic cells are broadly divided into "lymphoid" and "myeloid cells". Lymphoid cells include T cells, B cells, natural killer cells, and dendritic cells. Myeloid cells include red blood cells, platelets, monocytes/macrophages, and granulocytes (as well as other cell type such as eosinophils, mast cells, and basophils). A more detailed description of the initial stages of HSC differentiation is provided in Figure 2.

over a lifetime. Therefore, a stable pool of functional HSCs must be continuously maintained.

In order to do this, HSCs establish a balance between the processes of self-renewal, in which the daughter progeny of a dividing HSC retains the stem cell phenotype, and hematopoietic differentiation. It is proposed that the HSC achieves this balance by deciding between symmetric and asymmteric cell divisions. In symmetric division, the stem cell gives rise to identical daughter progeny, either both stem cells (self-renewal) or differentiating hematopoietic progenitors. In asymmetric cell division, the stem cell gives rise to one daughter stem cell and one daughter cell that differentiates. It is unknown whether the HSC undergoes asymmetric division in vivo although several in vitro studies have demonstrated using single cultured hematopoietic progenitors that up to $20 \%$ of the cell divisions from one cell to two cells are asymmetric [10-13]. There are examples of asymmetric stem cell division in vertebrates, notably in neural progenitor cells in the cortex [14] and in basal cells in fetal epidermis [15]. HSCs are generally quiescent, with $75 \%$ residing within the $\mathrm{G}_{0}$ phase of the cell cycle at any one time [16]. It has been estimated that about $8 \%$ of HSCs in mice enter the cell cycle every day and that every cell in the HSC population has gone through the cell cycle at least once every 3 months [16]. Regulation of proliferation is a key mediator of HSC numbers as mice deficient in the cell cycle inhibitory protein p 21 show increased HSC numbers [17].

The functional definition of an HSC is the ability to en- graft lethally irradiated recipients (the radiation treatment destroys the host bone marrow) and establish long-term (e.g., after 16 weeks in mice) multi-lineage hematopoiesis [18]. In such an assay, the donor cells must be detectable after 16 weeks in order to rule out any contribution by hematopoietic progenitors in the graft. Furthermore, the donor-derived cells must be detectable in all lineages, myeloid and lymphoid. These criteria can be met even when a single cell is transplanted, in which case a single transplanted HSC is responsible for generating approximately $1 \times 10^{8}$ cells [4, 19-21].

HSCs can be prospectively isolated from whole bone marrow through the use of flow cytometry to sort HSCs based on cell-surface phenotype (Figure 2). The depletion of lineage-committed blood cells ( $\mathrm{T}$ and $\mathrm{B}$ cells, macrophages, granulocytes, red blood cell precursors, etc.) from bone marrow leaves behind the lineage-negative, or lin', fraction which contains all HSCs and hematopoietic progenitors. In mice, the population of lin cells that highly express the cell surface proteins c-kit and Sca-1 (Lin', c$\mathrm{kit}^{\mathrm{HI}}$, Sca- ${ }^{\mathrm{HI}}$ or KSL) contain all HSCs [22]. Additional cell surface proteins such as Thy1.1, IL-7R $\alpha$, Flt3, CD150, and endoglin or the distinct dye-efflux profiles of Hoescht or Rhodamine can also be used to further enrich for HSCs [23-28]. The cell surface antigen CD34 can discriminate between long-term HSCs, which are CD34-, and short-term HSCs, which are CD $34^{+}[29,30]$. This contrasts with human long-term HSCs, which are enriched in a cell population with a $\mathrm{Lin}^{-}, \mathrm{CD} 34^{+}, \mathrm{CD} 38^{-}$phenotype $[31,32]$. 

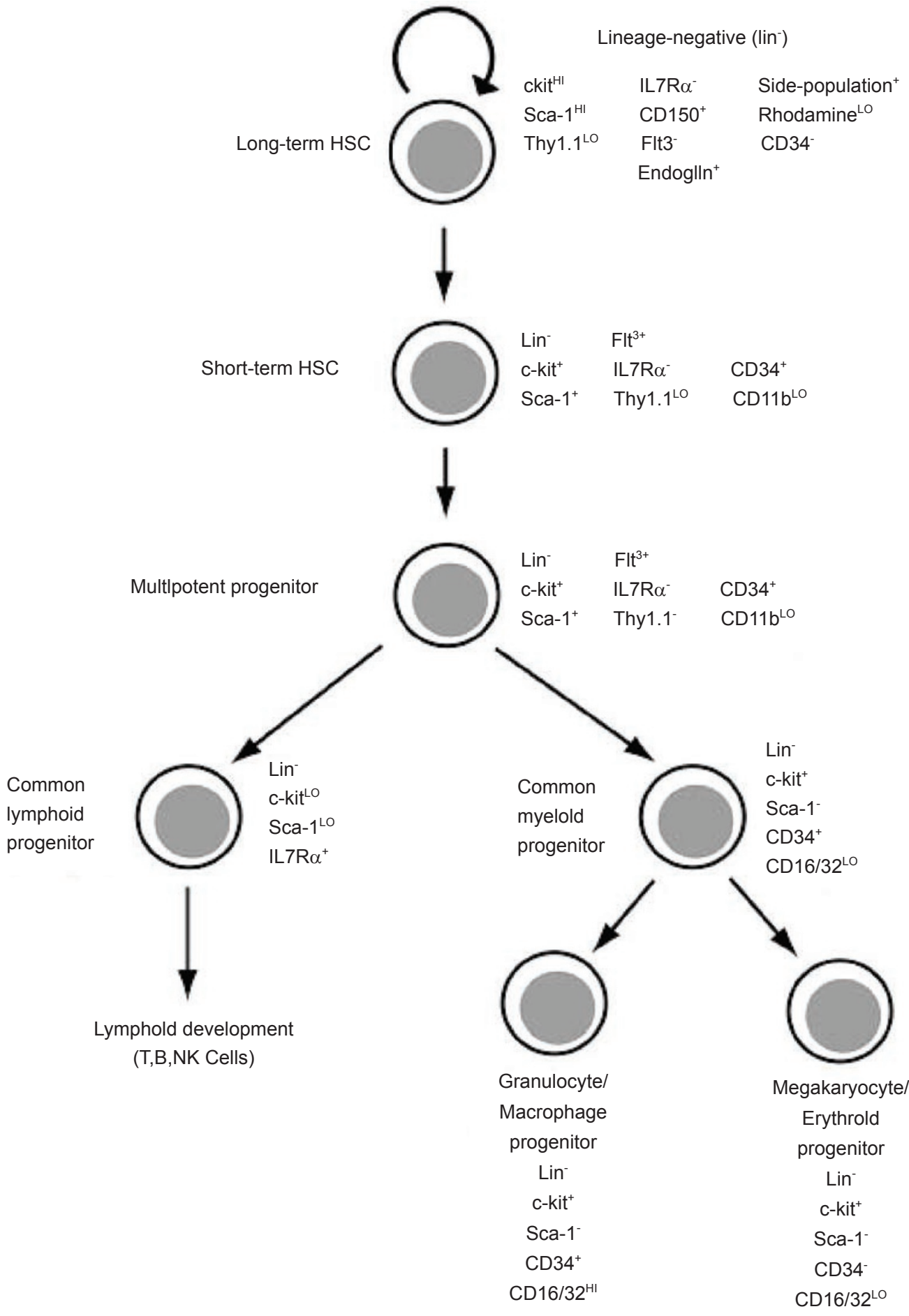

Figure $2 \mathrm{~A}$ model of the initial steps in hematopoiesis in adult mice along with some of the markers used to discriminate between HSCs and progenitors. "Side-population" refers to a distinct Hoescht efflux profile observed in long-term HSCs [27]. Long-term HSCs can be separated from short-term HSCs, which have limited self-renewal capacity (6-8 weeks) [23]. Multipotent progenitors are cells that can differentiate into all types of hematopoietic cells but have no self-renewal capability [156]. Common lymphoid progenitors can differentiate into all lymphoid lineages [24]. Common myeloid progenitors differentiate into progenitors than can differentiate into the granulocyte/macrophage and megakaryocyte/erythroid lineages, respectively [157]. The relationship between short-term HSCs, multipotent progenitors, and the oligopotent common lymphoid and myeloid progenitors is not definitively known and other studies have defined populations that fall outside those described in this figure (e.g., [158, 159]). 
The ontogeny of HSCs is still a controversial topic (for an extensive discussion of this topic, please see Cumano and Godin [33]). During development, hematopoiesis takes place in different organs at different stages. The first stage of hematopoiesis, called primitive hematopoiesis, takes place in the blood islands (a distinct aggregation of cells in which erythrocytes are surrounded by endothelial vascular cells) of the extra-embryonic yolk sac starting at approximately 7.5 days-post-coitus (d.p.c.) in the mouse [34]. Primitive hematopoiesis produces primitive erythrocytes, which are nucleated and contain embryonic hemoglobin [35-37]. By d.p.c. 12 in the mouse, the fetal liver is the site of definitive hematopoiesis, which is marked by the appearance of functional HSCs capable of producing enucleated red blood cells, the full complement of myeloid cells, and at later time points, lymphoid cells [38-40]. HSCs from the fetal liver colonize the bone marrow (starting at approximately d.p.c. 16.0 in the mouse), which becomes the final primary site of definitive hematopoiesis [41].

Initially, it was postulated that hematopoietic cells from the yolk sac colonized later sites of hematopoiesis, such as the fetal liver. Recently, Samokhvalov et al. [42] used an in vivo model that traced the developmental lineage of labeled d.p.c. 7.5 yolk sac cells to demonstrate that these cells produced hematopoietic progeny in fetal and adult mice indicating that hematopoietic cells in the yolk sac contribute towards the establishment of definitive hematopoiesis. However, these studies do not exclude the possibility that there is de novo generation of adult HSCs at other tissue sites. Definitive HSCs (defined by the ability to repopulate adult recipients) were observed at d.p.c. 10.5 near the aorta in a mesoderm-derived domain of the developing embryo called the aorta-gonad mesenephros (AGM) region and in the placenta [43-45]. Since circulation is established around d.p.c. 8.5, it is unclear whether the yolk sac, AGM, and placenta represent three independent sites of HSC development or whether colonization of one site by another has occurred [46].

\section{Wnt signaling pathways in hematopoiesis}

The maintenance of HSC pool requires a complex set of signals. Due to their ability to regulate multiple types of stem cells, the signals transduced by the Wnt family of proteins have proven to be of great interest in the study of HSC biology. Wnt ligands are a family of secreted glycoproteins (19 different Wnt genes in the mouse and human genomes) that are critical for normal development [47]. Multiple $W n t$ genes are expressed in bone marrow tissue, including Wnt2b, Wnt $3 a$, Wnt5a and Wnt10b [48-50]. Wnt ligands can activate multiple signaling pathways by binding to a member of the Frizzled family of receptors (10 different
Frizzled genes found in the mouse and human genomes) and the lipoprotein receptor-related protein (LRP) 5/6 coreceptors [51-53] (Figure 3). One Wnt signaling pathway, termed the canonical pathway, uses $\beta$-catenin as the critical signal transducer and is necessary for the formation of mesoderm, from which the hematopoietic system is derived [54]. In the absence of Wnt ligand binding, cytoplasmic $\beta$-catenin is sequestered in a multi-factor complex that includes the adenomatous polyposis coli (APC) tumor supressor protein, the scaffold protein Axin, and glycogen synthase kinase-3 $\beta$ (GSK-3 $\beta$ ) and casein kinase 1 (CK1) [55-58]. GSK-3 $\beta$ and CK1 phosphorylate $\beta$-catenin, which is recognized by the $\beta$-transducin repeat-containing homolog protein ( $\beta$-Trcp) $[59,60]$. $\beta$-Trcp targets $\beta$-catenin for degradation by the ubiquitin pathway [61-63]. Wnt binding to Frizzled induces phosphorylation of LRP 5/6 by membrane-bound GSK- $3 \beta$ and CK1 $\gamma$ (as opposed to the cytosolic forms that phosphorylate $\beta$-catenin and target it for degradation), which recruits Axin to the membrane where it physically interacts with LRP5/6, disrupting the multi-factor complex, and leading to $\beta$-catenin stabilization [64-66]. The intracellular Dishevelled protein is necessary for the recruitment of Axin to the membrane [67]. Upon stabilization, $\beta$-catenin translocates to the nucleus where it interacts with members of the T-cell factor (TCF)/lymphoid enhancer factor (LEF) family of transcription factors to induce target gene expression [68-70].

Initial experiments that studied the role of Wnt signaling in hematopoiesis focused on the functions of specific Wnt ligands found in the bone marrow rather than on the signaling pathways that they induced. Hematopoietic progenitors from mouse fetal liver displayed a three- to four-fold increase in the ability to form colonies of hematopoietic cells in vitro when cultured with conditioned media containing Wnt5a [50]. A similar experiment performed with lin', $\mathrm{CD} 34^{+}$human hematopoietic progenitors co-cultured with stromal cells transfected with $W N T 2 B, W N T 5 A$, or $W N T 10 B$ cDNA showed a 1.4- to 1.8 -fold increase in the frequency of primitive $\mathrm{CD}^{+} 4^{+}$cells in vitro [48]. Murdoch et al. [71] went on to show that injecting mice with Wnt5a-conditioned media prior to transplant of human umbilical cord blood cells increased engraftment more than three-fold.

Reya et al. [72] isolated Lin', c-kit ${ }^{\mathrm{HI}}, \mathrm{Sca}-1^{\mathrm{HI}}$ and Thy $1.1^{\mathrm{LO}}$ (KTSL) cells from mice overexpressing the anti-apoptotic $B C L-2$ gene and transduced them with a constitutively active form of $\beta$-catenin. This resulted in 20- to 48-fold in vitro expansion of KTSL cells for up to 2 months (compared to control KTSL cells which did not survive past $48 \mathrm{~h}$ ). KTSL cells transduced with constitutively active $\beta$-catenin and cultured for 1 week engrafted lethally irradiated recipients, while untransduced cells did not engraft. Willert et al. [73] cultured single KTSL cells with recombinant Wnt3a, 
A
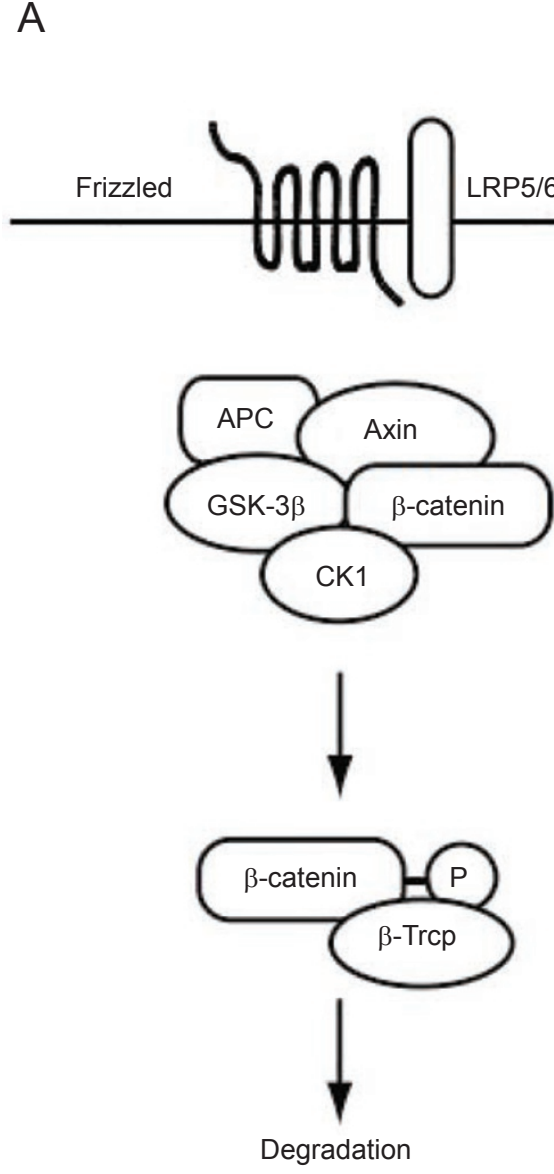

B
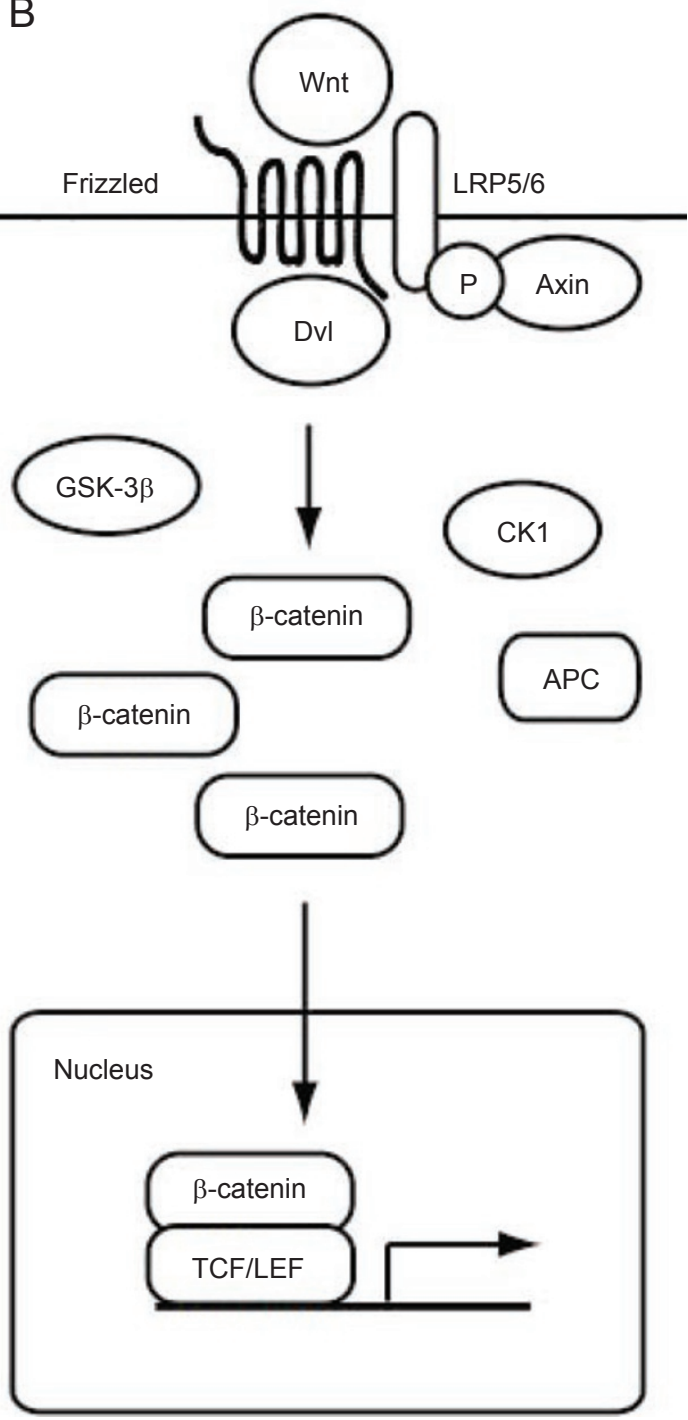

Figure 3 A schematic diagram of selected components of the canonical Wnt signaling pathways. (A) The absence of Wnt ligand binding to the Frizzled receptor and LRP 5/6 co-receptor enables the formation of a multi-protein complex (which includes APC, Axin, GSK-3 $\beta$, and $\mathrm{CK} 1$ ) that promotes the phosphorylation and subsequent degradation of $\beta$-catenin. In the absence of $\beta$-catenin translocation, repressor proteins bind to TCF/LEF transcription factors and prevent transcription from occurring. (B) In the presence of Wnt ligand, the LRP co-receptors are phosphorylated by membrane-bound casein kinase $1 \gamma$ and GSK-3 $\beta$ (not depicted), which recruits Axin to the cell membrane, disrupting the multi-protein complex. The Dishevelled protein (Dvl) is necessary for this process to occur but the mechanism is undefined. The disintegration of the multi-protein complex ultimately results in the accumulation and translocation of $\beta$-catenin to the nucleus. $\beta$-Catenin interacts with TCF/LEF and transcription occurs.

an activator of the canonical Wnt pathway, prior to transplant and showed that the presence of Wnt3a increased the frequency of hematopoietic reconstitution. HSCs deficient in the chromatin-binding protein Hmgb3 show increased expression of $D v l l$ (which encodes for Dishevelled 1) and exhibit increased canonical Wnt signaling which correlated with a bias towards self-renewal [74].
However, more recent studies have produced results that conflict with earlier interpretations on the actual role of the canonical Wnt pathway. Cobas et al. [75] showed that HSCs deficient in $\beta$-catenin retain their ability for selfrenewal and multilineage differentiation. However, this study did not address whether canonical Wnt signaling was also absent in $\beta$-catenin-deficient HSCs, leaving open the 
possibility that an alternative protein, such as $\gamma$-catenin, or an alternative signaling pathway, such as the TGF pathway which can also signal through TCF/LEF factors [76], might be able to partially compensate. Furthermore, this study only looked at whether the loss of $\beta$-catenin affected the ability of the HSC to reconstitute hematopoiesis in primary recipients and did not analyze whether $\beta$-catenin null HSCs from primary recipients could subsequently repopulate secondary or tertiary recipients, a more rigorous test of HSC function. Kincade and colleagues [77] showed that while transduction of an alternative form of constitutively active $\beta$-catenin prolonged survival (up to 5 months) and differentiation into multiple lineages of KSL cells in vitro, these cells were unable to engraft mice. Finally, Kirstteter $e t$ al. [78] and Scheller et al. [79] used two different transgenic models in which $\beta$-catenin was constitutively activated within HSCs. In both studies, constitutive canonical Wnt signaling inhibited multilineage differentiation and HSC self-renewal, leading to bone-marrow failure, indicating that too much canonical Wnt signaling has an adverse effect on HSC function. This suggests a model in which other signaling pathways act to balance the canonical Wnt pathway, either directly or indirectly.

Wnt ligands can also activate non-canonical signaling pathways; the pathway induced by a specific Wnt ligand mainly depends on the Frizzled receptor present. Several groups have shown that induction of non-canonical Wnt pathways can inhibit canonical signaling [80-83]. Topol et al. [82] has shown that induction of non-canonical Wnt signaling by Wnt5a promotes the GSK-3 $\beta$ independent ubiquitination and degradation of $\beta$-catenin through an APC-Siah2-Ebi E3 ubiquitin ligase complex. To see if a similar mechanism occurred in HSCs, we have cultured KSL cells under serum-free conditions for 6 days with recombinant Wnt3a and/or Wnt5a (Nemeth et al., manuscript submitted). While Wnt5a could promote $\beta$-catenin degradation and inhibit Wnt3a-induced canonical signaling, the presence of Wnt5a alone was sufficient to increase HSC engraftment efficiency and multilineage-repopulation compared to HSCs cultured without Wnt5a, indicating that non-canonical Wnt pathways are important for maintaining HSC function. Wnt5a enhanced the ability of HSCs to remain in the quiescent $\mathrm{G}_{0}$ phase, which improved their engraftment efficiency. Multiple studies have shown that $\mathrm{G}_{0}$ HSCs engraft and repopulate more efficiently than cycling HSCs [84-86]. The exact nature of the signaling pathway activated by Wnt5a in HSCs is still unknown. One possibility is a $\mathrm{G}$ protein coupled-increase in intracellular calcium (via cleavage of phosphatidylinositol 4,5-bisphosphate $\left(\mathrm{PI}(4,5) \mathrm{P}_{2}\right)$ by phospholipase $\left.\mathrm{C}-\beta\right)$, which then activates calcium-dependent kinases $[87,88]$. There are similarities between the effects of Wnt5a on HSCs and the reported functions of other G-protein coupled receptors (GPCRs) as pertains to cell proliferation and survival. CXCL12 is a chemokine that binds to the $\mathrm{G}$ protein-coupled CXCR4 receptor [89]. Induction of CXCL12 expression in human HSCs using DNA-damaging agents improved their engraftment and treatment of primitive hematopoietic progenitors with recombinant CXCL12 enhanced their in vitro survival in a p21-dependent mechanism [90, 91]. P2Y14, a member of a family of nucleotide GPCRs, is preferentially expressed in human fetal liver HSCs in the $\mathrm{G}_{0}$ phase and ectopic expression of the receptor in primitive human progenitors enhanced in vitro HSC function [92]. GPCRs also regulate the adhesion of HSCs within the bone marrow microenvironment, which is critical for their long-term maintenance. The CXCL12-CXCR4 axis is necessary for colonization of bone marrow by fetal HSCs as well as retention of HSCs within the adult bone marrow [93-95]. Recently, the G-protein-coupled calcium-sensing receptor was demonstrated to have a critical function in regulating adhesion of HSCs to their microenvironment [96]. Although stimulation of HSCs by recombinant Wnt5a did not enhance HSC homing, it is possible that there is a similar function of $\mathrm{Wnt} 5 \mathrm{a}$ in vivo in regulating adhesion of HSCs in the bone marrow via a G-protein-dependent mechanism

We also observed that Wnt5a can inhibit Wnt3a-mediated alterations in gene expression, such as increased myc expression [97], that have been linked to HSC differentiation, and this suggests a complementary in vivo model in which a balance between signaling by Wnt5a and Wnt3a is necessary for normal hematopoiesis to occur. This model may be especially relevant to the study of leukemias, hematologic disorders in which mutations (both somatic and germline) confer proliferative and survival advantages on HSCs and hematopoietic progenitors, inhibiting differentiation and promoting nearly limitless self-renewal. The clonal expansion of the malignant cells adversely affects the differentiation and function of the remaining normal hematopoietic cells, and these defects in normal hematopoiesis are the cause of the clinical symptoms. Mutations that activate canonical Wnt signaling have been reported for multiple solid tumors, e.g. $A P C$ in $85 \%$ of colorectal cancers $[98,99]$ and $C T N N B 1$ (which encodes for $\beta$-catenin) in $20 \%$ of hepatocellular carcinomas [100]. Therefore, it is not surprising that similar activation of the canonical Wnt pathway is observed in leukemic cells. Constitutive activation of the canonical Wnt pathway has been observed in samples from patients with acute myeloid leukemia (AML) and the expression of $\beta$-catenin correlates with poor prognosis [101, 102]. Thirty percent of AML patients bear the Flt3-ITD somatic mutation, the insertion of internal tandem duplications in the juxtamembrane domain of the Flt3 receptor [103]. This results in constitutive activation of the Flt3 receptor 
and, consequently, increased proliferation and survival of transformed cells $[104,105]$. The presence of Flt3-ITD is also associated with a poor prognosis [106]. Transfection of Flt3-ITD into 32Dcl3 cells activates canonical Wnt signaling, and $\beta$-catenin protein was present in 5/7 Flt3-ITD AML samples but absent in Flt3 wild-type AML samples, suggesting a mechanism for activation of canonical signaling in some AML sub-types [107].

Canonical Wnt signaling is also activated in cells from patients with blast-crisis chronic myeloid leukemia (CML) (i.e., CML in the terminal stages) [108]. Leukemic stem cells from CML patients exhibited decreased self-renewal and formation of hematopoietic colonies when transduced with a lentiviral vector expressing Axin, an inhibitor of canonical Wnt signaling. Ninety-five percent of CML patients carry the $\mathrm{t}(9,22)$ Philadelphia chromosome, a translocation event that results in the production of the $\mathrm{BCR}-\mathrm{ABL}$ fusion protein, which contributes to the clonal expansion of malignant hematopoietic progenitors [109, 110]. Studies have demonstrated a link between BCR-ABL and canonical Wnt signaling. Wild-type BCR (breakpoint cluster region) protein can act as a negative regulator of canonical Wnt signaling through a direct interaction with $\beta$-catenin $[111,112]$. The fusion of BCR and ABL (a tyrosine kinase) prevents this binding from occurring, possibly due to autophosphorylation, which allows Wnt signaling to proceed.

Approximately $3 \%$ of adults with acute lymphoblastic leukemia (ALL) display the E2A-Pbx1 fusion protein, which arrests normal B cell development [113]. E2A-Pbx 1 induces expression of Wnt16b [114]. Wnt16b induces canonical Wnt signaling and inhibition of Wnt16b in ALL cell lines resulted in increased apoptosis [115]. Recently, it was demonstrated that promoters for canonical Wnt pathway inhibitory genes (e.g., $s F R P-1$, Wif-1, and $D k k$-3) were abnormally methylated in ALL samples across a spectrum of genetic lesions [116]. This was associated with upregulation of canonical pathway genes Wnt 16, Frizzled 3, and Tcf-3 and nuclear localization of $\beta$-catenin. Abnormal methylation of Wnt pathway inhibitory genes was also associated with decreased rates of relapse-free and overall survival.

Finally, Liang et al. [117] showed that $W n t 5 a^{+/-}$mice were predisposed for developing myeloid and lymphoid leukemias (17/77 mice) that exhibited loss-of-heterozygosity of the remaining wild-type allele. 10/10 AML samples and 8/10 ALL samples showed reduced or absent expression of $W n t 5 a$ and increased expression of cyclin D1, a canonical Wnt pathway target gene. This study did not directly test the hypothesis that Wnt5a acts as a tumor supressor by inhibiting canonical Wnt signaling, although unfractionated fetal liver cells from $W n t 5 a^{-/-}$mice contained equivalent levels of $\beta$-catenin as their wild-type counter- parts. Ysebaert et al. [102] were unable to observe that expression of $W N T 5 A$ strictly correlated with the presence or absence of $\beta$-catenin protein, although this study did not present data correlating quantified levels of $W N T 5 A$ protein with levels of $\beta$-catenin protein.

\section{Canonical Wnt signaling and the osteoblast HSC niche}

Adult bone marrow is also home to non-hematopoietic cells, such as fibroblasts, adipocytes, endothelial cells, osteoblasts and stromal progenitors, which comprise the bone marrow microenvironment [118-120]. For over 30 years, it has been proposed that within the microenvironment, HSCs physically interact with biologically distinct cellular environments, called niches, which provide some of the external signals necessary for stem cell function [121]. The niche is a major determinant of whether a stem cell undergoes symmetric or asymmetric cell division. For example, in Drosophila ovaries and testes, the germ stem cell directly contacts a partner cell (cap cell in ovaries, hub cell in testes); after division, one cell remains in contact and has a stem cell phenotype whereas the daughter cell that is no longer in direct contact with its partner cell begins the differentiation program [122-124]. The mechanisms by which the niche regulates HSC fate at both the single cell and population levels are as yet incompletely defined.

Multiple cell types in the bone marrow microenvironment comprise the HSC niche. For example, recent studies have demonstrated that the bone marrow vasculature plays an important role in supporting HSCs $[25,125]$. However, for the remainder of this review, we will focus on the osteoblast, which is derived from the mesenchyme and initiates the process of ossification. Osteoblasts support hematopoiesis through the production of growth factors and have also been demonstrated to be critical components of the HSC niche [126-129]. HSCs have been demonstrated to preferentially reside at the endosteal surface of trabecular regions of bone (regions of more rapid bone remodeling, such as the ends of long bones), in contrast to more differentiated hematopoietic progenitors that are localized to the center of the bone marrow [128, 130, 131]. Zhang et al. [128] demonstrated that the HSC can physically interact with osteoblasts, specifically $\mathrm{N}$-cadherin ${ }^{+}$osteoblasts found in the trabecular bone area.

The necessity of osteoblasts for the normal function of the HSC niche was demonstrated by Visnjic et al. [132] in which osteoblasts were ablated in vivo using a transgenic model wherein the osteoblast-specific promoter for the Collal gene (which encodes for procollagen, type I, $\alpha 1$ ) was used to control the expression of thymidine kinase. Treating these mice with gancyclovir resulted in the loss 
of osteoblasts and, subsequently, decreased bone marrow cellularity and KSL cell number. There were increased numbers of progenitors in extramedullary sites, e.g. the spleen, peripheral blood, and liver, suggesting that HSCs took up residence in other tissue sites. These findings were not replicated using a transgenic model in which only developmentally mature osteoblasts were deleted (using the promoter for the Bglap1 gene, which encodes for osteocalcin and is induced during the onset of mineralization) [133]. This suggests that osteoblasts within HSC niches are developmentally immature. In the converse experiment, Calvi et al. [129] treated mice with parathyroid hormone, which at low doses leads to the anabolic formation of trabecular bone. This resulted in increased numbers of osteoblasts and HSCs in the bone marrow.

Several factors secreted by the osteoblast (as well as other cell types) have been implicated in the maintenance of HSCs. For example, osteoblasts produce Angiopoietin-1 (Ang-1), a soluble ligand that promotes angiogenesis by binding the receptor tyrosine kinase Tie2 [134]. The Ang1-Tie2 signaling axis also maintains HSC adhesion within the niche and promotes HSC quiescence [135]. Osteoblasts also secrete Jagged-1, a ligand for the Notch signaling pathway [129]. Studies have shown that activation of Notch signaling results in increased numbers of HSCs and hematopoietic progenitors in vitro and in vivo [136-138]. Another critical function of the niche is the ability to regulate HSC homing, i.e., the recruitment of HSCs to unoccupied stem cell niches, where the HSC engraftment and retention takes place [139]. The ability to HSCs to home to sites where they can engraft and initiate hematopoiesis is necessary during development when HSCs sequentially colonize the fetal liver and then the bone marrow. Furthermore, homing of HSCs to the niche is critical in bone marrow transplantation. Osteoblasts contribute to the regulation of HSC homing through the production of adhesion molecules that facilitate retention of the HSC in the niche, such as vascular cell-adhesion molecule 1 [140-142]. Osteoblasts also secrete CXCL12.

Therefore, developmental pathways that regulate the composition of the bone marrow microenvironment of the stem cell niche may indirectly regulate HSC function. The canonical Wnt signaling pathway is an excellent candidate for testing this model since it regulates the development of mesenchymal tissue, including the specific cell types found in the HSC niche, e.g. the osteoblast [143, 144]. Recent studies have demonstrated that canonical Wnt signaling plays a critical role in maintaining normal osteoblast differentiation. Using different transgenic models, Day et al. [144], Hill et al. [145], and Rodda and McMahon [146] all demonstrated that the loss of $\beta$-catenin inhibited osteogenic development during embryogenesis. In developmentally mature osteoblasts, the role of canonical Wnt signaling is less clear. In separate studies, deletion of $\beta$-catenin in mature osteoblasts led to osteopenia (reduced bone mass). Holmen et al. [147], using a Bglap1-Cre recombinase transgenic line to knockout $\beta$-catenin, detected decreased numbers of osteoblasts 4 weeks after birth. In contrast, Glass et al. [148], using a Collal-Cre line, observed no decrease in osteoblast numbers and that the resultant osteopenia was due to increased numbers of osteoclasts (bone marrow-derived cells that assist in the reabsorption of bone tissue). In human genetics, loss-of-function mutations in the LRP5 co-receptor cause osteoporosis-pseudoglioma syndrome, characterized in part by decreased bone mass. A mouse model of LRP5 deficiency displays a similar phenotype [149]. Autosomal gain-of-function mutations in LRP5 result in enhanced canonical Wnt signaling and increased bone density due to inhibition of the Dikkopf (Dkk) protein, a negative regulator of the canonical Wnt pathway $[150,151]$.

\section{Conclusions}

Although the past 10 years have seen progress on the role of Wnt signaling pathways in hematopoiesis, important questions still remain. As canonical Wnt signaling is active in several types of leukemia, are there signaling pathways that can directly or indirectly interact with the canonical Wnt pathway to promote leukemogenesis? What are the mechanisms by which non-canonical Wnt signals can maintain HSC function? Can canonical Wnt signals simply regulate the composition of the bone marrow microenvironment (such as osteoblasts) or are they necessary for normal function of the niche cells as well?

As described above, the role of canonical Wnt signaling in leukemia is an active area of study and molecules designed to disrupt this pathway may see use in the clinic [152]. One of the prominent features of the malignant hematopoietic disorder multiple myeloma is the development of osteolytic lesions due to enhanced bone destruction. Recent studies have demonstrated that myeloma cells secrete Dkk-1, an inhibitor of both canonical Wnt signaling and osteoblast differentiation and a potential pharmacologic target [153-155]. Therefore, further study of the role of the Wnt signaling pathways in HSC regulation will not only elucidate the mechanisms by which these unique cells function but may also prove useful in the design of novel therapeutic strategies to treat hematologic disorders.

\section{Acknowledgments}

We thank Dr Yingzi Yang (NIH/NHGRI) for insightful comments on the manuscript. Dr Michael Nemeth is sup- 
ported by the NIH/NHGRI intramural research program.

\section{References}

1 Fleischman RA, Custer RP, Mintz B. Totipotent hematopoietic stem cells: normal self-renewal and differentiation after transplantation between mouse fetuses. Cell 1982; 30:351-359.

2 Lemischka IR, Raulet DH, Mulligan RC. Developmental potential and dynamic behavior of hematopoietic stem cells. Cell 1986; 45:917-927.

3 Spangrude GJ, Heimfeld S, Weissman IL. Purification and characterization of mouse hematopoietic stem cells. Science 1988; 241:58-62.

4 Smith LG, Weissman IL, Heimfeld S. Clonal analysis of hematopoietic stem-cell differentiation in vivo. Proc Natl Acad Sci USA 1991; 88:2788-2792.

5 Brecher G, Neben S, Yee M, Bullis J, Cronkite EP. Pluripotent stem cells with normal or reduced self renewal survive lethal irradiation. Exp Hematol 1988; 16:627-630.

6 Harrison DE, Astle CM, Lerner C. Number and continuous proliferation pattern of transplanted primitive immunohematopoietic stem cells. Proc Natl Acad Sci USA 1988; 85:822-826.

7 van der Loo JC, van den Bos C, Baert MR, Wagemaker G, Ploemacher RE. Stable multilineage hematopoietic chimerism in alpha-thalassemic mice induced by a bone marrow subpopulation that excludes the majority of day-12 spleen colony-forming units. Blood 1994; 83:1769-1777.

8 Boggs DR. The total marrow mass of the mouse: a simplified method of measurement. Am J Hematol 1984; 16:277-286.

9 Ogawa M. Differentiation and proliferation of hematopoietic stem cells. Blood 1993; 81:2844-2853.

10 Suda J, Suda T, Ogawa M. Analysis of differentiation of mouse hemopoietic stem cells in culture by sequential replating of paired progenitors. Blood 1984; 64:393-399.

11 Takano H, Ema H, Sudo K, Nakauchi H. Asymmetric division and lineage commitment at the level of hematopoietic stem cells: inference from differentiation in daughter cell and granddaughter cell pairs. J Exp Med 2004; 199: 295-302.

12 Leary AG, Ogawa M, Strauss LC, Civin CI. Single cell origin of multilineage colonies in culture. Evidence that differentiation of multipotent progenitors and restriction of proliferative potential of monopotent progenitors are stochastic processes. J Clin Invest 1984; 74:2193-2197.

13 Leary AG, Strauss LC, Civin CI, Ogawa M. Disparate differentiation in hemopoietic colonies derived from human paired progenitors. Blood 1985; 66:327-332.

14 Qian X, Goderie SK, Shen Q, Stern JH, Temple S. Intrinsic programs of patterned cell lineages in isolated vertebrate CNS ventricular zone cells. Development 1998; 125:3143-3152.

15 Lechler T, Fuchs E. Asymmetric cell divisions promote stratification and differentiation of mammalian skin. Nature 2005; 437:275-280.

16 Cheshier SH, Morrison SJ, Liao X, Weissman IL. In vivo proliferation and cell cycle kinetics of long-term self-renewing hematopoietic stem cells. Proc Natl Acad Sci USA 1999; 96:3120-3125.

17 Cheng T, Rodrigues N, Shen H, et al. Hematopoietic stem cell quiescence maintained by $21 \mathrm{cip} 1 /$ waf1. Science 2000; 287:1804-1808.
18 Morrison SJ, Uchida N, Weissman IL. The biology of hematopoietic stem cells. Annu Rev Cell Dev Biol 1995; 11:35-71.

19 Osawa M, Hanada K, Hamada H, Nakauchi H. Long-term lymphohematopoietic reconstitution by a single CD34-low/negative hematopoietic stem cell. Science 1996; 273:242-245.

20 Wagers AJ, Sherwood RI, Christensen JL, Weissman IL. Little evidence for developmental plasticity of adult hematopoietic stem cells. Science 2002; 297:2256-2259.

21 Matsuzaki Y, Kinjo K, Mulligan RC, Okano H. Unexpectedly efficient homing capacity of purified murine hematopoietic stem cells. Immunity 2004; 20:87-93.

22 Ikuta K, Weissman IL. Evidence that hematopoietic stem cells express mouse c-kit but do not depend on steel factor for their generation. Proc Natl Acad Sci USA 1992; 89:1502-1506.

23 Christensen JL, Weissman IL. Flk-2 is a marker in hematopoietic stem cell differentiation: a simple method to isolate long-term stem cells. Proc Natl Acad Sci USA 2001; 98:14541-14546.

24 Kondo M, Weissman IL, Akashi K. Identification of clonogenic common lymphoid progenitors in mouse bone marrow. Cell 1997; 91:661-672.

25 Kiel MJ, Yilmaz OH, Iwashita T, et al. SLAM family receptors distinguish hematopoietic stem and progenitor cells and reveal endothelial niches for stem cells. Cell 2005; 121:1109-1121.

26 Chen CZ, Li M, de Graaf D, et al. Identification of endoglin as a functional marker that defines long-term repopulating hematopoietic stem cells. Proc Natl Acad Sci USA 2002; 99:1546815473.

27 Goodell MA, Brose K, Paradis G, Conner AS, Mulligan RC. Isolation and functional properties of murine hematopoietic stem cells that are replicating in vivo. J Exp Med 1996; 183:17971806.

28 Visser JW, Bauman JG, Mulder AH, Eliason JF, de Leeuw AM. Isolation of murine pluripotent hemopoietic stem cells. J Exp Med 1984; 159:1576-1590.

29 Yang L, Bryder D, Adolfsson J, et al. Identification of Lin(-) Sca1 (+) CD34(+) Flt3(-) short term hematopoietic stem cells capable of rapidly reconstituting and rescuing myeloablated transplant recipients. Blood 2005; 105:2717-2723.

3030 Osawa M, Hanada K, Hamada H, Nakauchi H. Long-term lymphohematopoietic reconstitution by a single CD34- low/ negative hematopoietic stem cell. Science 1996; 273:242-245.

31 Bhatia M, Wang JC, Kapp U, Bonnet D, Dick JE. Purification of primitive human hematopoietic cells capable of repopulating immune-deficient mice. Proc Natl Acad Sci USA 1997; 94:53205325.

32 Larochelle A, Vormoor J, Hanenberg H, et al. Identification of primitive human hematopoietic cells capable of repopulating NOD/SCID mouse bone marrow: implications for gene therapy. Nat Med 1996; 2:1329-1337.

33 Cumano A, Godin I. Ontogeny of the hematopoietic system. Annu Rev Immunol 2007; 25:745-785.

34 Haar JL, Ackerman GA. A phase and electron microscopic study of vasculogenesis and erythropoiesis in the yolk sac of the mouse. Anat Rec 1971; 170:199-223.

35 Craig ML, Russell ES. A developmental change in hemoglobins correlated with an embryonic red cell population in the mouse. Dev Biol 1964; 10:191-201.

36 Barker JE. Development of the mouse hematopoietic system. I. Types of hemoglobin produced in embryonic yolk sac and liver. 
Dev Biol 1968; 18:14-29.

37 Ingram VM. Embryonic red blood cell formation. Nature 1972; 235:338-339.

38 Johnson GR, Jones RO. Differentiation of the mammalian hepatic primordium in vitro. I. Morphogenesis and the onset of haematopoiesis. J Embryol Exp Morphol 1973; 30:83-96.

39 Delassus S, Cumano A. Circulation of hematopoietic progenitors in the mouse embryo. Immunity 1996; 4:97-106.

40 Traver D, Miyamoto T, Christensen J, et al. Fetal liver myelopoiesis occurs through distinct, prospectively isolatable progenitor subsets. Blood 2001; 98:627-635.

41 Ogawa M, Nishikawa S, Ikuta $\mathrm{K}$, et al. B cell ontogeny in murine embryo studied by a culture system with the monolayer of a stromal cell clone, ST2: B cell progenitor develops first in the embryonal body rather than in the yolk sac. EMBO J 1988; 7:1337-1343.

42 Samokhvalov IM, Samokhvalova NI, Nishikawa S. Cell tracing shows the contribution of the yolk sac to adult haematopoiesis. Nature 2007; 446:1056-1061.

43 Medvinsky A, Dzierzak E. Definitive hematopoiesis is autonomously initiated by the AGM region. Cell 1996; 86:897-906.

44 Ottersbach K, Dzierzak E. The murine placenta contains hematopoietic stem cells within the vascular labyrinth region. Dev Cell 2005; 8:377-387.

45 Gekas C, Dieterlen-Lievre F, Orkin SH, Mikkola HK. The placenta is a niche for hematopoietic stem cells. Dev Cell 2005; 8:365-375.

46 Ji RP, Phoon CK, Aristizabal O, et al. Onset of cardiac function during early mouse embryogenesis coincides with entry of primitive erythroblasts into the embryo proper. Circ Res 2003; 92:133-135.

47 Logan CY, Nusse R. The Wnt signaling pathway in development and disease. Annu Rev Cell Dev Biol 2004; 20:781-810.

48 Van Den Berg DJ, Sharma AK, Bruno E, Hoffman R. Role of members of the Wnt gene family in human hematopoiesis. Blood 1998; 92:3189-3202.

49 Reya T, O'Riordan M, Okamura R, et al. Wnt signaling regulates B lymphocyte proliferation through a LEF-1 dependent mechanism. Immunity 2000; 13:15-24.

50 Austin TW, Solar GP, Ziegler FC, Liem L, Matthews W. A role for the Wnt gene family in hematopoiesis: expansion of multilineage progenitor cells. Blood 1997; 89:3624-3635.

51 Bhanot P, Brink M, Samos CH, et al. A new member of the frizzled family from Drosophila functions as a Wingless receptor. Nature 1996; 382:225-230.

52 Pinson KI, Brennan J, Monkley S, Avery BJ, Skarnes WC. An LDL-receptor-related protein mediates Wnt signalling in mice. Nature 2000; 407:535-538.

53 Tamai K, Semenov M, Kato Y, et al. LDL-receptor-related proteins in Wnt signal transduction. Nature 2000; 407:530-535.

54 Haegel H, Larue L, Ohsugi M, et al. Lack of beta-catenin affects mouse development at gastrulation. Development 1995; 121:3529-3537.

55 Ikeda S, Kishida S, Yamamoto H, et al. Axin, a negative regulator of the Wnt signaling pathway, forms a complex with GSK-3beta and beta-catenin and promotes GSK-3beta- dependent phosphorylation of beta-catenin. EMBO J 1998; 17:1371-1384.

56 Sakanaka C, Weiss JB, Williams LT. Bridging of beta-catenin and glycogen synthase kinase-3beta by axin and inhibition of beta-catenin-mediated transcription. Proc Natl Acad Sci USA 1998; 95:3020-3023.

57 Ha NC, Tonozuka T, Stamos JL, Choi HJ, Weis WI. Mechanism of phosphorylation-dependent binding of APC to beta-catenin and its role in beta-catenin degradation. Mol Cell 2004; 15:511521.

58 Amit S, Hatzubai A, Birman Y, et al. Axin-mediated CKI phosphorylation of beta-catenin at Ser 45: a molecular switch for the Wnt pathway. Genes Dev 2002; 16:1066-1076.

59 Liu C, Li Y, Semenov M, et al. Control of beta-catenin phosphorylation/degradation by a dual-kinase mechanism. Cell 2002; 108:837-847.

60 Yost C, Torres M, Miller JR, et al. The axis-inducing activity, stability, and subcellular distribution of beta-catenin is regulated in Xenopus embryos by glycogen synthase kinase 3. Genes Dev 1996; 10:1443-1454.

61 Aberle H, Bauer A, Stappert J, Kispert A, Kemler R. Beta-catenin is a target for the ubiquitin-proteasome pathway. EMBO J 1997; 16:3797-3804.

62 Latres E, Chiaur DS, Pagano M. The human F box protein betaTrcp associates with the Cul1/Skp1 complex and regulates the stability of beta-catenin. Oncogene 1999; 18:849-854.

63 Liu C, Kato Y, Zhang Z, et al. Beta-Trcp couples beta-catenin phosphorylation-degradation and regulates Xenopus axis formation. Proc Natl Acad Sci USA 1999; 96:6273-6278.

64 Tamai K, Zeng X, Liu C, et al. A mechanism for Wnt coreceptor activation. Mol Cell 2004; 13:149-156.

65 Zeng X, Tamai K, Doble B, et al. A dual-kinase mechanism for Wnt co-receptor phosphorylation and activation. Nature 2005; 438:873-877.

66 Davidson G, Wu W, Shen J, et al. Casein kinase 1 gamma couples Wnt receptor activation to cytoplasmic signal transduction. Nature 2005; 438:867-872.

67 Cliffe A, Hamada F, Bienz M. A role of Dishevelled in relocating axin to the plasma membrane during wingless signaling. Curr Biol 2003; 13:960-966.

68 Miller JR, Moon RT. Analysis of the signaling activities of localization mutants of beta-catenin during axis specification in Xenopus. J Cell Biol 1997; 139:229-243.

69 Behrens J, von Kries JP, Kuhl M, et al. Functional interaction of beta-catenin with the transcription factor LEF-1. Nature 1996; 382:638-642.

70 van de Wetering M, Cavallo R, Dooijes D, et al. Armadillo coactivates transcription driven by the product of the Drosophila segment polarity gene dTCF. Cell 1997; 88:789-799.

71 Murdoch B, Chadwick K, Martin M, et al. Wnt-5A augments repopulating capacity and primitive hematopoietic development of human blood stem cells in vivo. Proc Natl Acad Sci USA 2003; 100:3422-3427.

72 Reya T, Duncan AW, Ailles L, et al. A role for Wnt signalling in self-renewal of haematopoietic stem cells. Nature 2003; 423:409414.

73 Willert K, Brown JD, Danenberg E, et al. Wnt proteins are lipidmodified and can act as stem cell growth factors. Nature 2003; 423:448-452.

74 Nemeth MJ, Kirby MR, Bodine DM. Hmgb3 regulates the balance between hematopoietic stem cell self-renewal and differentiation. Proc Natl Acad Sci USA 2006; 103:13783-13788.

75 Cobas M, Wilson A, Ernst B, et al. Beta-catenin is dispensable 
for hematopoiesis and lymphopoiesis. J Exp Med 2004; 199:221229.

76 Labbe E, Letamendia A, Attisano L. Association of Smads with lymphoid enhancer binding factor $1 / \mathrm{T}$ cell-specific factor mediates cooperative signaling by the transforming growth factor-beta and Wnt pathways. Proc Natl Acad Sci USA 2000; 97:8358-8363.

77 Baba Y, Yokota T, Spits H, et al. Constitutively active beta-catenin promotes expansion of multipotent hematopoietic progenitors in culture. J Immunol 2006; 177:2294-2303.

78 Kirstetter P, Anderson K, Porse BT, Jacobsen SE, Nerlov C. Activation of the canonical Wnt pathway leads to loss of hematopoietic stem cell repopulation and multilineage differentiation block. Nat Immunol 2006; 7:1048-1056.

79 Scheller M, Huelsken J, Rosenbauer F, et al. Hematopoietic stem cell and multilineage defects generated by constitutive beta-catenin activation. Nat Immunol 2006; 7:1037-1047.

80 Weidinger G, Moon RT. When Wnts antagonize Wnts. J Cell Biol 2003; 162:753-755.

81 Torres MA, Yang-Snyder JA, Purcell SM, et al. Activities of the Wnt-1 class of secreted signaling factors are antagonized by the Wnt-5A class and by a dominant negative cadherin in early Xenopus development. J Cell Biol 1996; 133:1123-1137.

82 Topol L, Jiang X, Choi H, et al. Wnt-5a inhibits the canonical Wnt pathway by promoting GSK-3-independent beta-catenin degradation. J Cell Biol 2003; 162:899-908.

83 Mikels AJ, Nusse R. Purified Wnt5a protein activates or inhibits beta-catenin-TCF signaling depending on receptor context. PLoS Biol 2006; 4:e115.

84 Fleming WH, Alpern EJ, Uchida N, et al. Functional heterogeneity is associated with the cell cycle status of murine hematopoietic stem cells. J Cell Biol 1993; 122:897-902.

85 Gothot A, van der Loo JC, Clapp DW, Srour EF. Cell cycle-related changes in repopulating capacity of human mobilized peripheral blood CD34(+) cells in non-obese diabetic/severe combined immune-deficient mice. Blood 1998; 92:2641-2649.

86 Ramshaw HS, Rao SS, Crittenden RB, et al. Engraftment of bone marrow cells into normal unprepared hosts: effects of 5fluorouracil and cell cycle status. Blood 1995; 86:924-929.

87 Kuhl M, Sheldahl LC, Malbon CC, Moon RT. Ca(2+)/calmodulin-dependent protein kinase II is stimulated by Wnt and Frizzled homologs and promotes ventral cell fates in Xenopus. J Biol Chem 2000; 275:12701-12711.

88 Sheldahl LC, Park M, Malbon CC, Moon RT. Protein kinase C is differentially stimulated by Wnt and Frizzled homologs in a G-protein-dependent manner. Curr Biol 1999; 9:695-698.

89 Bleul CC, Farzan M, Choe H, et al. The lymphocyte chemoattractant SDF-1 is a ligand for LESTR/fusin and blocks HIV-1 entry. Nature 1996; 382:829-833.

90 Ponomaryov T, Peled A, Petit I, et al. Induction of the chemokine stromal-derived factor- 1 following DNA damage improves human stem cell function. J Clin Invest 2000; 106:1331-1339.

91 Broxmeyer HE, Hangoc G, Cooper S, et al. AMD3100 and CD26 modulate mobilization, engraftment, and survival of hematopoietic stem and progenitor cells mediated by the SDF1/CXCL12-CXCR4 axis. Ann NY Acad Sci 2007; 1106:1-19.

92 Lee BC, Cheng T, Adams GB, et al. P2Y-like receptor, GPR105 (P2Y14), identifies and mediates chemotaxis of bone-marrow hematopoietic stem cells. Genes Dev 2003; 17:1592-1604.
93 Wright DE, Bowman EP, Wagers AJ, Butcher EC, Weissman IL. Hematopoietic stem cells are uniquely selective in their migratory response to chemokines. J Exp Med 2002; 195:1145-1154.

94 Ara T, Tokoyoda K, Sugiyama T, et al. Long-term hematopoietic stem cells require stromal cell-derived factor-1 for colonizing bone marrow during ontogeny. Immunity 2003; 19:257-267.

95 Foudi A, Jarrier P, Zhang Y, et al. Reduced retention of radioprotective hematopoietic cells within the bone marrow microenvironment in CXCR4-/- chimeric mice. Blood 2006; 107:2243-2251.

96 Adams GB, Chabner KT, Aller IR, et al. Stem cell engraftment at the endosteal niche is specified by the calcium-sensing receptor. Nature 2006; 439:599-603.

97 Wilson A, Murphy MJ, Oskarsson T, et al. c-Myc controls the balance between hematopoietic stem cell self-renewal and differentiation. Genes Dev 2004; 18:2747-2763.

98 Groden J, Thliveris A, Samowitz W, et al. Identification and characterization of the familial adenomatous polyposis coli gene. Cell 1991; 66:589-600.

99 Nishisho I, Nakamura Y, Miyoshi Y, et al. Mutations of chromosome $5 \mathrm{q} 21$ genes in FAP and colorectal cancer patients. Science 1991; 253:665-669.

100 Giles RH, van Es JH, Clevers H. Caught up in a Wnt storm: Wnt signaling in cancer. Biochim Biophys Acta 2003; 1653:1-24.

101Simon M, Grandage VL, Linch DC, Khwaja A. Constitutive activation of the Wnt/beta-catenin signalling pathway in acute myeloid leukaemia. Oncogene 2005; 24:2410-2420.

102 Ysebaert L, Chicanne G, Demur C, et al. Expression of betacatenin by acute myeloid leukemia cells predicts enhanced clonogenic capacities and poor prognosis. Leukemia 2006; 20:1211-1216.

103 Kiyoi H, Towatari M, Yokota S, et al. Internal tandem duplication of the FLT3 gene is a novel modality of elongation mutation which causes constitutive activation of the product. Leukemia 1998; 12:1333-1337.

104Tse KF, Mukherjee G, Small D. Constitutive activation of FLT3 stimulates multiple intracellular signal transducers and results in transformation. Leukemia 2000; 14:1766-1776.

105 Mizuki M, Fenski R, Halfter H, et al. Flt3 mutations from patients with acute myeloid leukemia induce transformation of 32D cells mediated by the Ras and STAT5 pathways. Blood 2000; 96:39073914.

106Kondo M, Horibe K, Takahashi Y, et al. Prognostic value of internal tandem duplication of the FLT3 gene in childhood acute myelogenous leukemia. Med Pediatr Oncol 1999; 33:525-529.

107Tickenbrock L, Schwable J, Wiedehage M, et al. Flt3 tandem duplication mutations cooperate with Wnt signaling in leukemic signal transduction. Blood 2005; 105:3699-3706.

108 Jamieson CH, Ailles LE, Dylla SJ, et al. Granulocyte-macrophage progenitors as candidate leukemic stem cells in blast-crisis CML. N Engl J Med 2004; 351:657-667.

109Konopka JB, Watanabe SM, Singer JW, Collins SJ, Witte ON. Cell lines and clinical isolates derived from $\mathrm{Ph1}$-positive chronic myelogenous leukemia patients express c-abl proteins with a common structural alteration. Proc Natl Acad Sci USA 1985; 82:1810-1814.

110 Sawyers CL. Chronic myeloid leukemia. N Engl J Med 1999; 340:1330-1340.

111 Ress A, Moelling K. Bcr is a negative regulator of the Wnt 
signalling pathway. EMBO Rep 2005; 6:1095-1100.

112 Ress A, Moelling K. Bcr interferes with beta-catenin-Tcf1 interaction. FEBS Lett 2006; 580:1227-1230.

113 Ferrando AA, Look AT. Clinical implications of recurring chromosomal and associated molecular abnormalities in acute lymphoblastic leukemia. Semin Hematol 2000; 37:381-395.

$114 \mathrm{McWhirter}$ JR, Neuteboom ST, Wancewicz EV, et al. Oncogenic homeodomain transcription factor E2A-Pbx1 activates a novel WNT gene in pre-B acute lymphoblastoid leukemia. Proc Natl Acad Sci USA 1999; 96:11464-11469.

115 Mazieres J, You L, He B, et al. Inhibition of Wnt16 in human acute lymphoblastoid leukemia cells containing the $\mathrm{t}(1 ; 19)$ translocation induces apoptosis. Oncogene 2005; 24:5396-5400.

116Roman-Gomez J, Cordeu L, Agirre X, et al. Epigenetic regulation of WNT signaling pathway in acute lymphoblastic leukemia. Blood 2007; 109:3462-3469.

117 Liang H, Chen Q, Coles AH, et al. Wnt5a inhibits B cell proliferation and functions as a tumor suppressor in hematopoietic tissue. Cancer Cell 2003; 4:349-360.

118 Weiss L. The hematopoietic microenvironment of the bone marrow: an ultrastructural study of the stroma in rats. Anat Rec 1976; 186:161-184.

119Dexter TM, Allen TD, Lajtha LG. Conditions controlling the proliferation of haemopoietic stem cells in vitro. J Cell Physiol 1977; 91:335-344.

120 Lichtman MA. The ultrastructure of the hemopoietic environment of the marrow: a review. Exp Hematol 1981; 9:391-410.

121 Schofield $\mathrm{R}$. The relationship between the spleen colony-forming cell and the haemopoietic stem cell. Blood Cells 1978; 4:7-25.

$122 X i e$ T, Spradling AC. A niche maintaining germ line stem cells in the Drosophila ovary. Science 2000; 290:328-330.

123 Kiger AA, White-Cooper H, Fuller MT. Somatic support cells restrict germline stem cell self-renewal and promote differentiation. Nature 2000; 407:750-754.

124 Yamashita YM, Jones DL, Fuller MT. Orientation of asymmetric stem cell division by the APC tumor suppressor and centrosome. Science 2003; 301:1547-1550.

125 Heissig B, Hattori K, Dias S, et al. Recruitment of stem and progenitor cells from the bone marrow niche requires MMP-9 mediated release of kit-ligand. Cell 2002; 109:625-637.

126 Taichman RS, Emerson SG. Human osteoblasts support hematopoiesis through the production of granulocyte colony-stimulating factor. J Exp Med 1994; 179:1677-1682.

127 Taichman RS, Reilly MJ, Emerson SG. Human osteoblasts support human hematopoietic progenitor cells in vitro bone marrow cultures. Blood 1996; 87:518-524.

128Zhang J, Niu C, Ye L, et al. Identification of the haematopoietic stem cell niche and control of the niche size. Nature 2003; 425:836-841.

129Calvi LM, Adams GB, Weibrecht KW, et al. Osteoblastic cells regulate the haematopoietic stem cell niche. Nature 2003; 425:841-846.

130Lord BI, Testa NG, Hendry JH. The relative spatial distributions of CFUs and CFUc in the normal mouse femur. Blood 1975; 46:65-72.

131 Nilsson SK, Johnston HM, Coverdale JA. Spatial localization of transplanted hemopoietic stem cells: inferences for the localization of stem cell niches. Blood 2001;97:2293-2299.

132 Visnjic D, Kalajzic Z, Rowe DW, et al. Hematopoiesis is severely altered in mice with an induced osteoblast deficiency. Blood 2004; 103:3258-3264.

133 Corral DA, Amling M, Priemel M, et al. Dissociation between bone resorption and bone formation in osteopenic transgenic mice. Proc Natl Acad Sci USA 1998; 95:13835-13840.

134 Suri C, Jones PF, Patan S, et al. Requisite role of angiopoietin-1, a ligand for the TIE2 receptor, during embryonic angiogenesis. Cell 1996; 87:1171-1180.

135 Arai F, Hirao A, Ohmura M, et al. Tie2/angiopoietin-1 signaling regulates hematopoietic stem cell quiescence in the bone marrow niche. Cell 2004; 118:149-161.

136 Varnum-Finney B, Xu L, Brashem-Stein C, et al. Pluripotent, cytokine-dependent, hematopoietic stem cells are immortalized by constitutive Notch1 signaling. Nat Med 2000; 6:1278-1281.

137Stier S, Cheng T, Dombkowski D, Carlesso N, Scadden DT. Notch1 activation increases hematopoietic stem cell self-renewal in vivo and favors lymphoid over myeloid lineage outcome. Blood 2002; 99:2369-2378.

138Duncan AW, Rattis FM, DiMascio LN, et al. Integration of Notch and Wnt signaling in hematopoietic stem cell maintenance. Nat Immunol 2005; 6:314-322.

139Nilsson SK, Simmons PJ. Transplantable stem cells: home to specific niches. Curr Opin Hematol 2004; 11:102-106.

140 Craddock CF, Nakamoto B, Andrews RG, Priestley GV, Papayannopoulou T. Antibodies to VLA4 integrin mobilize long-term repopulating cells and augment cytokine-induced mobilization in primates and mice. Blood 1997; 90:4779-4788.

141 Kikuta T, Shimazaki C, Ashihara E, et al. Mobilization of hematopoietic primitive and committed progenitor cells into blood in mice by anti-vascular adhesion molecule-1 antibody alone or in combination with granulocyte colony-stimulating factor. Exp Hematol 2000; 28:311-317.

142Zhu J, Garrett R, Jung Y, et al. Osteoblasts support B lymphocyte commitment and differentiation from hematopoietic stem cells. Blood 2007 Epub.

143 Guo X, Day TF, Jiang X, et al. Wnt/beta-catenin signaling is sufficient and necessary for synovial joint formation. Genes Dev 2004; 18:2404-2417.

144Day TF, Guo X, Garrett-Beal L, Yang Y. Wnt/beta-catenin signaling in mesenchymal progenitors controls osteoblast and chondrocyte differentiation during vertebrate skeletogenesis. Dev Cell 2005; 8:739-750.

145 Hill TP, Spater D, Taketo MM, Birchmeier W, Hartmann C. Canonical Wnt/beta-catenin signaling prevents osteoblasts from differentiating into chondrocytes. Dev Cell 2005; 8:727-738.

146Rodda SJ, McMahon AP. Distinct roles for Hedgehog and canonical Wnt signaling in specification, differentiation and maintenance of osteoblast progenitors. Development 2006; 133:3231-3244.

147Holmen SL, Zylstra CR, Mukherjee A, et al. Essential role of beta-catenin in postnatal bone acquisition. J Biol Chem 2005; 280:21162-21168.

148Glass DA II, Bialek P, Ahn JD, et al. Canonical Wnt signaling in differentiated osteoblasts controls osteoclast differentiation. Dev Cell 2005; 8:751-764.

149 Gong Y, Slee RB, Fukai N, et al. LDL receptor-related protein 5 (LRP5) affects bone accrual and eye development. Cell 2001; 107:513-523.

150Boyden LM, Mao J, Belsky J, et al. High bone density due to a 
mutation in LDL-receptor-related protein 5. N Engl J Med 2002; 346:1513-1521.

151 Ai M, Holmen SL, van Hul W, et al. Reduced affinity to and inhibition by DKK1 form a common mechanism by which high bone mass-associated missense mutations in LRP5 affect canonical Wnt signaling. Mol Cell Biol 2005; 12:4946-4955.

152 Lepourcelet M, Chen YN, France DS, et al. Small-molecule antagonists of the oncogenic Tcf/beta-catenin protein complex. Cancer Cell 2004; 5:91-102.

153 Tian E, Zhan F, Walker R, et al. The role of the Wnt-signaling antagonist DKK1 in the development of osteolytic lesions in multiple myeloma. N Engl J Med 2003; 349:2483-2494.

154 Terpos E, Heath DJ, Rahemtulla A, et al. Bortezomib reduces serum dickkopf-1 and receptor activator of nuclear factor-kappaB ligand concentrations and normalises indices of bone remodelling in patients with relapsed multiple myeloma. Br J Haematol 2006; 135:688-692.
155 Yaccoby S, Ling W, Zhan F, et al. Antibody-based inhibition of DKK1 suppresses tumor-induced bone resorption and multiple myeloma growth in vivo. Blood 2007; 109:2106-2111.

156Morrison SJ, Wandycz AM, Hemmati HD, Wright DE, Weissman IL. Identification of a lineage of multipotent hematopoietic progenitors. Development 1997; 124:1929-1939.

157 Akashi K, Traver D, Miyamoto T, Weissman I. A clonogenic common myeloid progenitor that gives rise to all myeloid lineages. Nature 2000; 404:193-197.

158C Cumano A, Paige CJ, Iscove NN, Brady G. Bipotential precursors of B cells and macrophages in murine fetal liver. Nature 1992; 356:612-615.

159Adolfsson J, Mansson R, Buza-Vidas N, et al. Identification of Flt3 + lympho-myeloid stem cells lacking erythro-megakaryocytic potential a revised road map for adult blood lineage commitment. Cell 2005; 121:295-306. 